\title{
The factors influence the intention to use mobile applications for room-sharing in Vietnam
}

\author{
Hoa Vu Dinh ${ }^{a}$ and Anh Nguyen Thi Ngoc ${ }^{b^{*}}$
}

${ }^{\mathrm{a}}$ Faculty of Tourism Studies, PHENIKAA University, Hanoi 12116, Vietnam

${ }^{b}$ Faculty of Human Resource Management, University of Labour and Social Affairs, Hanoi 12116, Vietnam

\section{CH RON I CLE A B S T RACT}

\section{Article history:}

Received: March 10, 2021

Received in revised format: June

3, 2021

Accepted: August 31, 2021

Available online: August 31, 2021

Keywords:

UTAUT2

Mobile apps

Room sharing

Intention to use

Vietnam

\begin{abstract}
This study analyzes the factors affecting the intention of using mobile applications (apps) for roomsharing in Vietnam. The research model is inherited and developed based on the unified theoretical model of technology acceptance and use (UTAUT2) by the specific conditions of Vietnam. The analysis results from 346 users show that the intention to use mobile apps for room-sharing services in Vietnam is influenced by expected benefits (i); expected effort (ii); social influence (iii), hedonic motivation (iv), trust (v), and perceived security (vi). Expected benefits, hedonic dynamics, and expected security have an important influence on the using intention among these factors; thus, application providers need a valuable solution to enhance the functionality of their applications on these aspects to meet the customers' increasing requirements.
\end{abstract}

\section{Introduction}

The advent of the internet and the continuous development of technology have influenced many areas of social life (Khan, Al-Shihi, Al-Khanjari \& Sarrab, 2015). Based on technology, new economic models appear one after another, typically the sharing economy model. More and more people are willing to share their property for others to use through online platforms (Botsman and Rogers, 2011). The development of many sharing economy models stems from advances in information and communication technology (ICT), the popularity of social networking, and changes in consumer attitude, transferring from the need of possessing to access and experience (Botsman \& Rogers, 2011; Wang et al., 2012). In tourism, sharing economy models are developing and forming a fully worked out sharing ecosystem (Hoa, 2020; Fernando et al., 2013). Users can share the vehicles (Car2go, Zipcar), eating (Eatwith), travel guides (Vayable), and housing (Airbnb, Booking.com, Homeaway). Room sharing is one of the most developed activities because it brings outstanding benefits in terms of economy (cheaper than hotels) and social (integration with the local community). (Guttentag, 2015). The room-sharing model is very successful and develops strength in the world, especially in developed countries. Thanks to the high popularity and flexibility combined with smart apps with simple and user-friendly interfaces, mobile apps for room-sharing are more interesting and widely applied. The mobile apps include software, programmed programs for smartphones, tablets, music players, and other mobile devices to perform certain functions to meet user's needs. (Islam \& Mazumder, 2010; Mehdipour \& Zerehkafi, 2013). Mobile apps are easy to use, user-friendly, cost-effective, and downloadable for a wide range of devices (Nah \& Sheng, 2005). The technologies integrated into mobile apps are increasingly diversified and superior (Hwang \& Wu, 2014), including wireless technologies such as Wi-Fi, Bluetooth, etc., and global telecommunication connection systems such as GPS, GSM, GPRS,

* Corresponding author.

E-mail address: ngocanh.hrm@gmail.com (A. N. T. Ngoc) 
3G, CDMA with the same platform, cloud computing, and server system; AR - VR simulation technologies (Mehdipou, 2013; Fernado, Loke \& Rahayu, 2013). Many scientists worldwide and in Vietnam have discussed the research on the sharing economy model in tourism and room-sharing apps. However, the discussed studies mainly focus on the current situation and development prospects of the room-sharing model or a specific room-sharing application. The research on the intention to use and the factors affecting the intention to use mobile apps on room-sharing in tourism is minimal, almost not mentioned. Thus, the three research contents of this paper aim to include: (i) building a theoretical framework model on the factors affecting the intention to use of mobile apps on room-sharing; (ii) Measuring the influence of factors on it and (iii) Proposing essential solutions to increase this for room-sharing in Vietnam shortly.

\section{Theoretical framework}

\subsection{Intention to use and acceptance model using UTAUT2 technology}

Behavioral intention (BI) refers to "a person's subjective probability that he will perform some behavior" (Ajzen, 1991; Ajzen and Fishbein, 2000) that motivates and demonstrates an individual's available effort willing to perform a particular behavior. The intention to use mobile applications is the ability of users to use applications regularly and continuously on mobile devices in the future (Webster et al., 1993; Venkatesh \& Davis, 2000; O'Connor \& Andrews, 2018). The acceptance and use of technology are an inevitable part of scientific and technological innovation. Based on eight component models/theories, which are Theory Of Reasoned Action(TRA or Tora), Theory of Planned Behavior (TPB), Technology Acceptance Model (TAM, TAM2), Motivation Model (MM), Combined TAM, and TPB (TAM\&TPB), the Model of Personal Computer Utilization (MPCU), Innovation Diffusion Theory (IDT), and Social Cognitive Theory (SCT), Venkatesh et al. (2003) proposed a unified theoretical model of technology acceptance and use (UTAUT) including three factors that have a direct impact on behavioral intentions (performance expectancy, effort expectancy, and social influence) and two factors that directly affect actual usage behavior (facilitating conditions and behavioral purposes). Besides, the mediating factors: Gender, age, experience, and voluntariness of use indirectly affect behavioral intention and use behavior through the main factors. However, in the context of increasingly developing information technology, Venkatesh et al. (2012) continued to work out and set the UTAUT2 model entirely. The UTAUT2 model was developed based on the original structure of UTAUT but changed some existing relationships, adding three new relationships: Hedonic Motivation and Price Value and Habit. UTAUT2 removed the variable "voluntariness of use" and added the combination between convenience and behavioral intention to use.

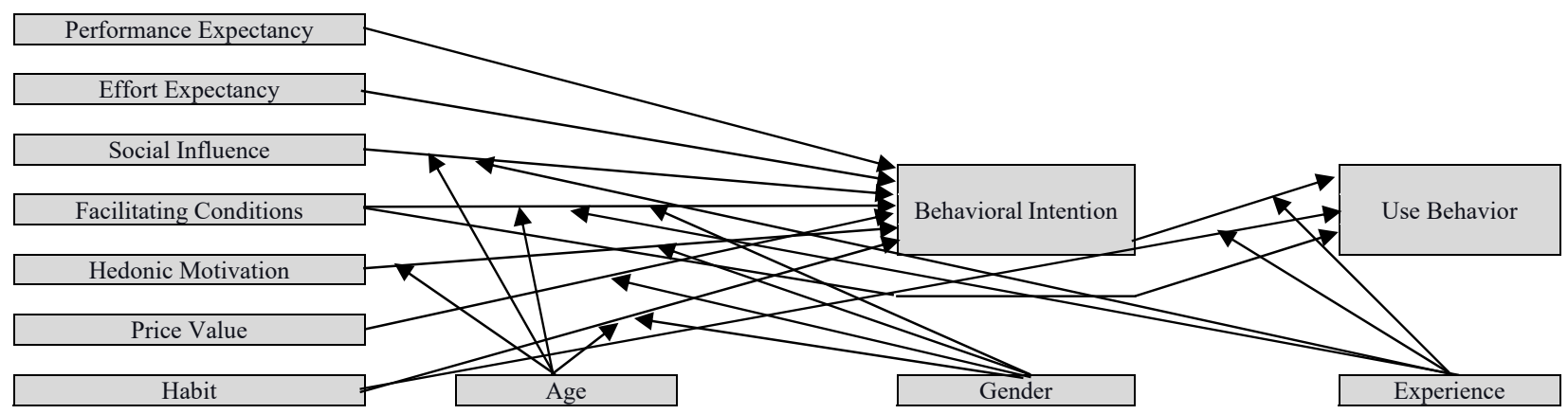

Fig 1. UTAUT2 model. (Venkatesh et al., 2012)

\subsection{Proposed research model}

Based on the UTAUT2 model in the context of the development of information technology, the practice of developing and using mobile apps for room-sharing in Vietnam. The author proposes the following specific research hypotheses:

\section{(i) Effect of expectancy-value theory on intention to use}

The expectancy-value theory is defined as how an individual believes that using the system will help the user achieve more excellent job benefits (Davis et al., 1989). In this study, the expectancy-value implies that users realize advantages from using mobile applications in room-sharing. The benefits that customers can get from using room-sharing mobile apps can be more than from traditional booking services. The benefits of using room-sharing mobile apps can help customers save time and costs and access various services (Davis, 1993, Pavlou et al., 2006, Erkan \& Evans, 2016). Expectancy-value is identified as a factor that directly affects the intention to use technology products, including mobile applications (Park et al., 2014). When users feel the apps are helpful, they will have a positive attitude and use the application more (Choi et al., 2011). Therefore, the following hypothesis has been proposed:

\section{$\mathbf{H}_{1}$ : Expectancy-value positively affects intention to use mobile apps for room-sharing.}


In UTAUT2, effort expectancy can be defined as "the degree of ease associated with the use of the system". According to Vankatesh et al. (2003), this factor stems from the perceived ease of use proposed in the technology acceptance model. Davis et al. (1989) show that a cognitive application by an individual that can easily use them is likely to accept them. In this study, effort expectancy is understood as the expected effort related to ease of login and use of room-sharing mobile apps. In information technology, effort expectancy is also the user's perception and evaluation of system characteristics such as flexibility when interacting with the system (Venkatesh and Davis, 2000), ease of learning operations usability, and clarity of the interface (Genfen, 2000). Effort expectancy positively influences attitudes and intentions to use mobile apps (Fortest \& Rita, 2016; Pavlou \& Fygenson, 2006; Hawlitschek et al., 2016). Therefore, the following hypothesis has been proposed:

\section{$\mathbf{H}_{2}$ : Effort expectancy positively influences the intention to use mobile apps for room-sharing.}

\section{(iii) The impact of social influence on intention to use}

Social influence is defined as how the individual perceives those significant others believe they should use the new system. In this study, social influence is understood as the impact of others on the individual's perception that will substantially impact the intention to use mobile apps for room sharing. The choice to use is significantly influenced by friends and family members (Singh et al.,2010). Many researchers have shown that people who use mobile apps have been influenced by people around them. In other words, social influence is a factor that has a positive influence on the intention to use mobile apps. Therefore, the following hypothesis has been proposed:

\section{H3: Social influence positively influences the intention to use mobile apps for room-sharing.}

iv) The influence of facilitating conditions on intention to use and use behavior

Facilitating conditions are defined as the degree to which an individual believes that the necessary resources are needed to support the use of the system (Venkatesh et al., 2012). In this study, facilitation conditions are understood as the degree to which an individual believes that they can support the service system of the mobile apps about room-sharing. Many studies have also shown that favorable conditions positively affect behavioral intention to use technology. Therefore, the following hypothesis has been proposed:

\section{H4: Facilitation conditions positively influence the intention to use the mobile apps for room-sharing.}

\section{(v) The influence of hedonic motivation on intention to use}

Hedonic motivation is defined as the perceived enjoyment resulting from privately using technology and finding some predictable usefulness or effectiveness (Davis, 1993). Hedonic motivation has a direct impact on technology acceptance and use (Venkatesh et al.,2012). This study defined hedonic motivation as pleasure using room-sharing mobile apps and perceived usefulness or predictable effectiveness. Many studies have shown that hedonic motivation influences technology acceptance. Therefore, the following hypothesis has been proposed:

\section{H5: Hedonic motivation positively influences the intention to use the mobile apps of room-sharing.}

\section{vi) The influence of trust on intention to use.}

Trust is vital to any business relationship (Wang et al., 2015), and it plays a crucial role in e-commerce because it reduces uncertainty (Wang et al., 2015). Trust in mobile apps about room-sharing can influence their intention to use and behavior; if there is no trust, there is no acceptance and use of this service (Zhou, 2012; Jeng et al., 2010). In this study, faith is understood as customers' trust in transaction information with innkeepers through mobile apps for room-sharing. Trust in the service is considered, including initial confidence and subsequent trust after using the service. The mobile apps of room-sharing have just developed in Vietnam in recent years, and this trust can be considered very important in the current context. Therefore, the following hypothesis has been proposed:

\section{$\mathbf{H}_{6}$ : Trust positively influences the intention to use mobile apps for room-sharing.}

\section{(vii) The influence of perceived security (PS) on trust and intention to use}

Most online consumers have a top concern on security, and it is related to their privacy. Thus, the protection of information is essential. In this study, perceived security when using the room-sharing apps is understood as the customer's perception of the ability of the application provider could protect their confidential information, which the provider has from electronic transactions from being stolen, disclosed, and used without the customer's consent (Kim et al., 2008; Moon \& Kim, 2001). When the platform provider guarantees information security policies and commitments, customers feel safe when transacting, and their trust in online transactions increases. Therefore, the following hypothesis has been proposed: 
$\mathbf{H}_{7}$ : Perceived security positively influences the intention to use mobile apps for room-sharing.

Based on the developed hypotheses, the research model is formed, as shown in Figure 2. The variables in the research model are shown in Table 1.

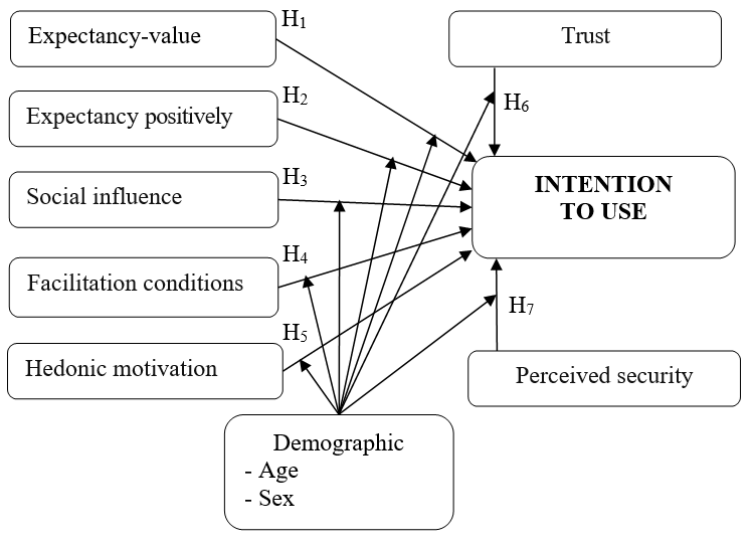

Fig. 2. Research model

Source: Proposed Research

Table 1

Variables in the research model

\begin{tabular}{|c|c|c|}
\hline No. & Content & Source of scales \\
\hline \multicolumn{3}{|c|}{ 1. Expectancy-value } \\
\hline EV1 & Do you think that using mobile apps for room-sharing optimizes cost benefits? & Venkatesh et al., (2012), Liang (2015). \\
\hline EV2 & Do you think that using mobile apps for room sharing brings comfort during use? & \\
\hline EV3 & Do you think that using mobile apps for room-sharing saves your time? & \\
\hline EV4 & Do you think that mobile apps for room-sharing help you updated information quickly? & \\
\hline \multicolumn{3}{|c|}{ 2. Effort expectancy } \\
\hline EE1 & Do you think that the mobile apps for room-sharing have a simple and user-friendly interface? & Davis (1993), \\
\hline EE2 & Do you think that the operation of mobile apps for room-sharing is easy to understand? & Gefen et al., (2003), \\
\hline EE3 & Do you think that it is easy to learn how to work on room-sharing mobile apps? & Venkatesh et al., $(2003,2012)$. \\
\hline EE4 & Do you think that the interaction with mobile apps for room-sharing is flexible? & \\
\hline
\end{tabular}

3. Social influence

SI1 Do you think that essential person around influences your use of room-sharing mobile apps?
SI2 Do you think that the people around you have an influence on the user behavior of mobile apps for
SI3 $\quad$ Doom-sharing?

4. Facilitation conditions

FC1 Do you think that you have the necessary resources to use mobile apps for room-sharing? Venkatesh et al., (2012).

FC2 Do you think that you have the necessary knowledge to use mobile apps for room-sharing?

FC3 Do you think that you have the necessary support services to use room-sharing mobile apps?

5. Hedonic motivation

$\begin{array}{ll}\text { HM1 } & \text { Do you enjoy using mobile apps for room-sharing? } \\ \text { HM2 } & \text { Do you feel interested in using mobile apps for room-sharing? } \\ \text { HM3 } & \text { Do you think using room-sharing mobile apps is a memorable experience? } \\ \text { HM4 } & \text { Do you think the use of mobile apps for room-sharing brings satisfaction to you? }\end{array}$

6. Trust

TR1 Do you think mobile apps for room-sharing to be reliable?

TR2 Do you trust that the mobile apps for room-sharing will provide you with the best services?

Kim et al., (2008), Jarvenpaa et al., (1999,

Do you trust that the mobile apps for room-sharing will provid
Do you have to worry about using mobile apps for room sharing?

2000).

TR4 Do you feel good and safe room-sharing mobile apps to do your transactions?

7. Perceived security

Do you believe that your personal Information in your transactions with room-sharing mobile apps is Kim et al., (2008).

PS1 secure?

PS2 Do you feel safe sharing your personal information through room-sharing mobile apps?

PS3 you believe that mobile apps for room-sharing will not use your personal information without your permission?

PS4

Do you believe that mobile apps for room-sharing can ensure that personal information is not sent to the 3 rd parties?

8. Intention to use

IU1 Do you think you would like to experience the features of mobile apps for room sharing (if possible)?

IU2 Will you intend to continue using mobile apps for room-sharing in the future?

Davis (1993), Belanger and

Will you intend to use mobile apps for room-sharing in the long term and frequency?

Carter (2008), Venkatesh (2012), Oliveira et

IU3

Will you share the positive aspects and encourage friends and relatives to join and use mobile apps for al., (2016).

IU4 room-sharing? 


\section{Data and methods}

\subsection{Research data}

This article uses secondary data sources inherited from published researchers' documents and statistical websites Statista.com, AirDNA data, and other reliable sources. For primary data, Hair et al. (2010) showed that it ensures the sample size is consistent with the EFA analysis method; the number of observations must be at least 4-5 times the number of variables. This is also consistent with the view of many studies that the needed ratio to design the sample size is a minimum of five observations per estimator (ratio 5:1). Meanwhile, the minimum sample size to be achieved for multivariate regression analysis is calculated by the formula $\mathrm{n}=50+8 \times \mathrm{p}$ (p: the number of latent factors) (Tabachnick \& Fidell, 2006; Pappas et al., 2017). Alternatively, the sampling rule can be based on the variable error based on the comprehensive study (Suanders et al., 2007; Ahn et al., 2007). Within the scope of the research, the authors applied a sample size of over 346, which is suitable for the model and the survey accessibility for 30 observed variables and eight latent variables. This sample size applies the 5-fold rule of exploratory factor analysis of EFA $(5 \times 30=150)$, the least for multivariate regression analysis $(50+8 \times 8=114)$. Research data was carried out in two stages: (i) conducting interviews with 03 experts and 100 respondents by questionnaires via email to evaluate the scales preliminarily. The results obtained 93 valid responses; (ii) formal investigation via email and google forms. After one month of research, the author collected 88 responses via email and 258 valid online onces (346 responses in total) for analysis.

\subsection{Data analysis methods}

After collecting, research data is coded and cleaned; the author uses multivariate data analysis methods to analyze and test the research hypotheses with SPSS and AMOS software.

\section{Research and discussion results}

\subsection{Sample descriptive statistics results}

The study considers classifying customers participating in the survey according to the criteria of gender, age, occupation, and time of using mobile devices. In 346 valid votes, the results of demographic statistics are shown in the following table:

Table 2

Demographic characteristics of survey respondents

\begin{tabular}{|c|c|c|c|}
\hline Group & Description & Number of people & Ratio \\
\hline \multirow{2}{*}{ Gender } & Male & 149 & 43.1 \\
\hline & Female & 197 & 56.9 \\
\hline \multirow{4}{*}{ Age } & Under 20 & 53 & 15.3 \\
\hline & From $21-30$ & 187 & 54.1 \\
\hline & From 31-50 & 70 & 20.4 \\
\hline & Over 50 & 36 & 10.2 \\
\hline \multirow{4}{*}{ Occupation } & Pupil/Student & 65 & 18.7 \\
\hline & Back office staffs & 112 & 32.5 \\
\hline & Salesman & 91 & 26.4 \\
\hline & Others & 78 & 22.4 \\
\hline \multirow{4}{*}{ Time of using mobile devices } & Under 1 hour & 260 & 75.1 \\
\hline & From 1-3 hours & 64 & 18.5 \\
\hline & From 3-5 hours & 18 & 5.2 \\
\hline & Over 5 hours & 4 & 1.2 \\
\hline
\end{tabular}

(Survey results, 2020)

The survey result shows that in terms of gender, the number of male and female customers participating in the survey is relatively equal, with $43.1 \%$ and $56.9 \%$, respectively. Regarding age, respondents are relatively young, from 30 years old or younger, nearly $70 \%$. In particular, the group of customers over 50 years accounted for the lowest rate of $10.2 \%$, the age group with the highest proportion was the group from 21 to 30 years old, recorded at $40.1 \%$. The occupational characteristics show that the majority of respondents are office staff and salesmen with $58.9 \%$ of the total valid responses, in which the rate of each group is $32.5 \%$ and $36.4 \%$, respectively. These numbers have a relative association with age classification results. Other occupational groups including self-employed, university lecturers, housewives, retirees, etc., answered the questionnaires with a comparable proportion of about $22.4 \%$. Most respondents have less than 1 hour of mobile time with a ratio of $75.1 \%$, followed by the group from 1 to 3 hours accounting for $18.5 \%$, and over 5 hours accounting for a tiny percentage of $1.2 \%$. 
Regarding the use of room-sharing mobile apps of the users, the study evaluates and classifies according to the criteria: (i) awareness of house-sharing services, (ii) the number of people who know about the sharing platforms, (iii) reasons for staying, (iv) length of stay, and (v) media to share experiences during trips. The results of descriptive statistics according to the above five criteria are shown in Table 3.

Table 3

Customers' characteristics of using mobile apps for room-sharing

\begin{tabular}{|c|c|c|c|}
\hline Group & Description & Number of people & Ratio \\
\hline \multirow{2}{*}{ Awareness } & Used & 260 & 75.1 \\
\hline & Unused & 86 & 24.9 \\
\hline \multirow{5}{*}{$\begin{array}{l}\text { Number of people who experience } \\
\text { room-sharing mobile apps }\end{array}$} & Airbnb & 158 & 45.8 \\
\hline & Luxstay & 35 & 10.2 \\
\hline & West & 57 & 16.5 \\
\hline & HomeAway & 64 & 18.2 \\
\hline & Others & 32 & 9.3 \\
\hline \multirow{5}{*}{ Reasons for staying } & Travel & 243 & 70.1 \\
\hline & Business/ Trip & 53 & 15.2 \\
\hline & Studying & 37 & 10.6 \\
\hline & Relatives visiting & 12 & 3.5 \\
\hline & Others & 1 & 0.6 \\
\hline \multirow{3}{*}{ Length of stay } & Some days - 1 week & 307 & 88.6 \\
\hline & From 1 - 2 weeks & 27 & 7.9 \\
\hline & Over two weeks & 12 & 3.5 \\
\hline \multirow{4}{*}{$\begin{array}{l}\text { Media to share experiences during } \\
\text { trips }\end{array}$} & Email/ Message about the trip & 22 & 6.3 \\
\hline & Photos/videos sent to friends and relatives & 78 & 22.6 \\
\hline & Photos/videos posted on the Public Internet & 191 & 55.3 \\
\hline & Write a review on the Internet about the trip & 55 & 15.8 \\
\hline
\end{tabular}

The house-sharing service characteristics demonstrate that about two-thirds of users know about the house-sharing service with $75.1 \%$. The rest, a relative proportion of people, have not used the apps about room-sharing. Regarding mobile apps related to room-sharing in Vietnam, the most popular is Airbnb, with a known rate of $45.8 \%$, which is superior to the speed of other platforms such as Westay $(16.5 \%)$, Homeaway $(18.2 \%)$, and Luxstay $(10.2 \%)$. Among the valid votes, some users know more than one platform, even know all platforms, and know some other platforms like Couchsurfing and Booking.com. For the general behavioral characteristics of users when traveling and renting accommodation, the most chosen reason for this activity is to travel with $70.1 \%$. In addition, few customers want to rent a place for work, business trip with $25.9 \%$ or studying with $24.7 \%$. In terms of time, most trips are short with $88.6 \%$ of users experiencing a period of a few days to a week, followed by the number of people traveling with a duration of 1-2 weeks accounting for $7.9 \%$, the rest staying for more than two weeks accounting for only $3.5 \%$. The means used by customers to share their experiences of trips are pretty diverse and widespread; the most popular sharing activity is posting photos/videos on the Internet for relatives, friends, and others to see, accounting for over a half of users with $55.3 \%$.

\subsection{Preliminary assessment results of the scale}

The assessment results with the preliminary sample $(n=93)$ show that the factors in the research model are reliable and unidirectional scales. As shown in Table 4 below, The Cronbach Alpha coefficients are all greater than 0.7, the total correlation of the observed variables is more significant than 0.3 , the KMO coefficients are greater than 0.5 , the factor loading is more important than 0.5, Bartlett's test shows the statistical significance and total variance of explained (TVE) is greater than $50 \%$.

Table 4

Preliminary assessment results of the scale

\begin{tabular}{|c|c|c|c|c|c|c|}
\hline Factor & Cronbach Alpha & $\begin{array}{c}\text { Corrected } \\
\text { Item-Total } \\
\text { Correlation }\end{array}$ & КМO & p-value & AVE (\%) & Factor Loading \\
\hline Expectancy-value & .871 & .728 & .818 & .000 & 70,91 & .767 \\
\hline Effort expectancy & .820 & .653 & .879 & .000 & 60,62 & .850 \\
\hline Facilitating conditions & .873 & .507 & .823 & .000 & 74,78 & .795 \\
\hline Social influence & .789 & .728 & .798 & .000 & 61,93 & .650 \\
\hline Hedonic motivation & .761 & .468 & .771 & .000 & 65,86 & .758 \\
\hline Trust & .801 & .634 & .714 & .000 & 62,12 & .784 \\
\hline Perceived security & .850 & .675 & .897 & .000 & 70,19 & .668 \\
\hline
\end{tabular}


The preliminary scale assessment with a sample size of 93 supports that the research concepts are reliable and consistent with the research data. The study used the confirmatory factor analysis method with a critical model to evaluate the scale with the official sample $(n=346)$. The scales were evaluated by confirmatory factor analysis $(\mathrm{CFA})$ with the critical model to evaluate the convergence value, the compatibility of the research model with the actual data, and the discriminant value among the factors. The $\mathrm{p}$-values of the observed variables all have sig. $=0.00$. Thus, the observed variables can represent well for the CFA model factor. CFA results Chi-square/df $=1.343$ less than $3 ; \mathrm{GFI}=0.921 ; \mathrm{CFI}=0.932 ; \mathrm{IFI}=0.973$ are greater than 0.9 . The factor weights of the observed variables are greater than 0.5 , showing that the research concepts reach the convergence value, the confidence interval of $95 \%$ of the correlation coefficients in the bootstrap analysis does not contain the value one shows that the research concepts have discriminatory value. The combined reliability of the factors is greater than 0.6 , showing that the research concepts are reliable with official data.

\subsection{Structural modeling and testing of research hypotheses}

The results of the Structural Equation Modeling (SEM) analysis showed that the measurement values of chi-square/df $=1,782$ $<2$; CFI $=0.946$, TLI $=0.935$; IFI $=0.947$ are greater than 0.9 ; and RMSEA $=0.057<0.08$ show that the SEM structural model is consistent between theory and reality, which means it is suitable for the market. The results in the form of data on regression coefficients of the SEM show that the factor influences the intention to use mobile apps for room-sharing. The factor "facilitating conditions" has sig. $=0.074>0.5$ has no statistical significance at reliability of $95 \%$ (Table 5). Therefore, the study removed the facilitating condition factor (rejecting hypothesis Fig.4) and accepted other hypotheses.

Table 5

The regression coefficients of SEM

\begin{tabular}{|c|c|c|c|c|c|c|}
\hline & & & Estimate $^{*}$ & S.E. & C.R. & $\mathbf{P}$ \\
\hline EV & $\rightarrow$ & $\mathrm{IU}$ & .354 & .051 & 5.757 & $* * *$ \\
\hline $\mathrm{EE}$ & $\rightarrow$ & IU & .131 & .038 & 2.151 & .010 \\
\hline $\mathrm{FC}$ & $\rightarrow$ & IU & .171 & 0.30 & 1.873 & 0.81 \\
\hline SI & $\rightarrow$ & IU & .114 & .047 & 2.528 & $* * *$ \\
\hline HM & $\rightarrow$ & IU & .255 & .068 & 4.516 & $* * *$ \\
\hline TR & $\rightarrow$ & IU & .152 & .040 & 3.800 & $* * *$ \\
\hline PS & $\rightarrow$ & IU & .234 & .031 & 5.774 & $* * *$ \\
\hline
\end{tabular}

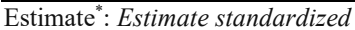

${ }^{* * *}:$ statistically significant

Table 4 shows that the intention to use mobile apps for room-sharing in Vietnam tourism is influenced by expectancy-value, effort expectancy, social influence, hedonic motivation, trust, and perceived security. In this study, the facilitating conditions do not affect the intention to use the mobile apps for room-sharing. Thus, it is excluded from the model.

\subsection{Results of testing the impact of age and gender on the intention to use mobile apps for room-sharing}

The test of age difference on intention to use mobile apps on room-sharing: The results of the variable model analysis reveal a difference between the ages for the influencing factors on the choice to use the mobile apps of room-sharing. For the group under 30 years old, expectancy-value, hedonic motivation, social influence, and perceived security strongly impact intention to use mobile apps for room-sharing. While in the age group from 31 to 50 are without much difference among factors. For the age group over 50, perceived security, trust, and effort expectancy significantly influence; expectancy-value and social impact elements have little effect. Testing the gender difference for the factors that influence the intention to use the mobile apps on room-sharing: The test results show a difference between men and women for the effort expectancy and expectancy value. Men think that the more accessible service is to use, the more they intend to use it, but women are not affected by this factor. Men are not affected by expectation-value, but women believe that the higher expectancy-value, they are more likely to use them.

\section{Discussion of research results and solutions to increase the intention to use mobile apps on room-sharing in Vietnam tourism}

The research results on demographics of survey subjects show that: (i) the age of people using mobile apps for room-sharing is currently mainly youth under 30 years old with $69.4 \%$ this age group has approached and used mobile apps for roomsharing more than middle-aged and older people. This age group can access technology quickly and is willing to pioneer in accessing new technologies. Thus, the usage rate is often higher than the middle and elderly groups. The study results on the age difference between the factors affecting the intention to use mobile apps on house-sharing also show differences in effort expectancy and expectancy-value. Young people are often affected by expectancy-value and social influence, while middleaged and older people are not affected much. Meanwhile, effort expectancy, perceived security, trust, and hedonic motivation affect middle-aged and older people. (ii) Regarding gender, the proportion of female users is higher than male users, which 
shows that men with unused mobile apps for room sharing are high. The results of testing the influencing factors show that men are affected by the ease of use while women are not affected because women are possibly more careful than men.

Regarding the characteristics of customers using room-sharing services, it shows that: (i) For the awareness of house-sharing platforms, Airbnb is most well-known with a rate of 45.8\%, outperforming other platforms such as Westay (16.5\%), Homeaway $(18.2 \%)$ and Luxstay (10.2\%). This result is quite relevant as Airbnb is currently the most powerful and oldest housesharing platform globally. Airbnb is also the most prominent platform in Vietnam, so it has the advantage of brand recognition over the media that come later. (ii) Regarding travel and house-renting habits in general, the biggest reason is tourism demand, with the rate of customers choosing $70.1 \%$. They were followed by work/business reasons $(15.2 \%)$ and study (10.6\%). This is a good result because the house-sharing service mainly serves the experiencing needs of new, different, and intimate spaces, especially developing in prominent tourist destinations such as Hanoi, Ho Chi Minh, Da Nang, Vung Tau, Da Lat, Nha Trang. (iii) Up to $88.6 \%$ of customers rent short-term housing (from a few days to a week), which shows the compatibility with the reasons for travel and house-renting. (iv) The most popular media used to share the stay experiences are photos and videos, especially those posted on the Internet, with a rate of 55.3\%. Email, messages, or writing reviews are not very popular, with rates of $3.5 \%$ and $15.8 \%$, respectively. This result may be that taking photos/videos is a simple way of sharing, storing for a long time, and attracting a lot of attention when sharing with the community about the trip experience.

Regarding the factors influencing the intention to use the mobile apps of room-sharing:

The expectancy-value is the factor that has the most decisive influence on the intention to use room-sharing apps $(b=0.324)$ (because the percentage of respondents is mainly youth under 30 years old). When the perception of performance expectancy was increased by 1 point, the intention to use the mobile apps about room-sharing increased by 0.343 issues that affect the choice to use mobile apps about room-sharing. This finding conforms to prior research performed by Venkatesh (2012) as well as recent research on the intention to participate in the sharing economy by Hamari et al. (2015), Wang et al. (2017), Tussyadiah (2016). Accordingly, the providers of mobile apps for room-sharing need to pay attention to accuracy, friendliness, improve user experience interaction and utilities when using the apps that help users save time and effort in choosing roomsharing services that meet their requirements. Hedonic motivation is the second most crucial factor influencing using mobile apps for room sharing $(b=0.255)$. Hedonic motivation is the user's pleasure in using the service. If customers think that the mobile apps about room-sharing have exciting things, they will have a higher intention to use them. This finding agrees with previous work by Venkatesh (2012). This shows that the eye-catchingness of the apps, the interface of the apps, and the convenience of the service that brings the user's interest has a significant influence on the choice of the apps.

The perceived security plays a crucial role in affecting intention to use mobile apps for room-sharing $(b=0.234)$. Therefore, application providers need to have security measures according to modern technology, enhance security for users with strict and precise security terms and build a security system for user information. Effort expectancy significantly affects the intention to use mobile apps for room sharing $(b=0.131)$. Customers think that the more straightforward to use room-sharing mobile apps, the more likely they are to use them. Therefore, the application providers need to simplify input operations, focus on describing simple functions, and diversify instruction forms. Besides, the application providers also need to set up a customer care system that directly answers, solves problems, and supports users in discovering new products' new features. Trust significantly influences performance expectancy, hedonic motivation, security, and effort expectancy $(b=0.152)$. This is a good result, similar to the proposed theories of Theory of Reasoned Action (Ajzen \& Fisbein, 1975), theory of planned behavior (Ajzen, 1985, 1991), integrative model of organizational trust (Mayer, Davis \& Schoorman, 1995), and also found in the findings of empirical research on trust on online platforms by Kim et al. (2008), Lu et al. (2010). To increase customers' intention to use, the providers need to improve and maintain the quality of Information on apps, promote and improve the quality of Information on apps through strict control of input information, check and update helpful Information that customers need, and periodically re-evaluate Information. Social influence has the minor power among the six factors $(b=0.114)$. However, the suppliers also need to promote marketing activities through social connections such as advertising, interactive communication, engaging with users, coordinating with online and direct advertising.

\section{Conclusion}

Based on inheriting the UTAUT2 theory, the study proposes a model of factors influencing using mobile apps for roomsharing in Vietnam tourism. In the context of research in Vietnam, the study has presented models of factors influencing the intention to use mobile apps for room-sharing, including (i) expectancy-value, (ii) effort expectancy, (iii) facilitating conditions, (iv) social influence, (v) hedonic motivation (vi) trust and (vii) perceived security. At the same time, the study provided data and analysis results of factors influencing the intention to use mobile apps for room-sharing and showed that facilitating conditions (UTAUT2) do not affect the choice to use and demonstrate that "expectancy-value, hedonic motivation, and expected security significantly influence on intention to use. In addition, the study also assessed the impact of demographic variables (gender, age) on the intention to use mobile apps on room-sharing. Based on determining the influence level of each factor and the different influences of each age and gender, the research has suggested some solutions of mobile apps for the application providers about room-sharing in the business in Vietnam. 
An inherent limitation to this study could be posed by the sample used, although the purpose of the study has been achieved. Firstly, the study is only conducted in some provinces in Vietnam. Thus the generalizability of the study may be limited. Secondly, cultural aspects have not been mentioned while studying the factors influencing the intention to use room-sharing apps. Therefore, it is necessary to supplement and expand the model's variables in further studies to better explain the intention to use mobile apps for room-sharing.

\section{References}

Ahn, T., Ryu, S., \& Han, I. (2007). The impact of Web quality and playfulness on user acceptance of online retailing. Information \& Management, 44(3), 263-275.

Ajzen, I. (1991). The theory of planned behavior. Organizational Behavior and Human Decision Processes, 50(2), $179-211$.

Ajzen, I., \& Fishbein, M. (2000). Attitudes and the attitude-behavior relation: Reasoned and automatic processes. European Review of Social Psychology, 11(1), 1-33.

Bélanger, F., \& Carter, L. (2008). Trust and risk in e-government adoption. The Journal of Strategic Information Systems, 17(2), 165-176.

Botsman, R., \& Rogers, R. (2011), What's Mine Is Yours: How Collaborative Consumption is Changing the Way We Live, HarperCollins Business, London: Collins. p. 51.

Choi, J. Y., Kim, Y. B., Jun, Y. M., \& Kim, Y. H. (2011). A Bayesian Multivariate Probit Analysis of Korean Firms' Information System Adoption. Industrial Management \& Data Systems, 111(9), 1465-1480.

Davis, F. D., Bagozzi, R. P., and Warshaw. P.R, (1989), Use acceptance of computer technology: a comparison of two theoretical models. Management Science, 35(8), 982 - 1003

Davis, F. D. (1993). User acceptance of information technology: system characteristics, user perceptions, and behavioral impacts. International Journal of Man-Machine Studies, 38(3), 475-487.

Erkan, I., \& Evans, C. (2016). The influence of eWOM in social media on consumers' purchase intentions: A comprehensive approach to information adoption. Computers in Human Behavior, 61, 47-55

Fernando, N., Loke, S. W., \& Rahayu, W. (2013), Mobile cloud computing: A survey. Future Generation Computer Systems, 29(1), 84-106.

Fortes, N., \& Rita, P. (2016). Privacy concerns and online purchasing behavior towards an integrated model. European Research on Management and Bussiness Economics, 22(3), 167 - 176.

Gefen, D. (2000). E-commerce: the role of familiarity and trust. Omega, 28(6), 725-737.

Guttentag, D. (2015). Airbnb: disruptive innovation and the rise of an informal tourism accommodation sector. Current Issues in Tourism, 18, 1192-1217.

Kim, D.J., Ferrin, D.L., \& Rao, H.R. (2008). A trust-based consumer decision-making model in electronic commerce: The role of trust, perceived risk, and their antecedents. Decision Support Systems, 44(2), 544-564.

Kim, J., Yoon, Y., \& Zo, H. (2015). Why People Participate in the Sharing Economy: A Social Exchange Perspective. In PACIS (p. 76).

Khan, A. I., Al-Shihi, H., Al-Khanjari, Z. A., \& Sarrab, M. (2015). Mobile Learning (M-Learning) adoption in the Middle East: Lessons learned from the educationally advanced countries. Telematics and Informatics, 32(4), 909-920.

Hamari, J., Sjöklint, M., \& Ukkonen, A. (2016). The Sharing Economy: Why People Participate in Collaborative Consumption, Journal of the Association for Information Science and Technology, 67(9), 2047-2059.

Hair, J. F., Anderson, R. E., Babin, B. J., \& Black, W. C. (2010). Multivariate data analysis: A global perspective. Pearson Education, London.

Hawlitschek, F., Teubner, T. and Gimpel, H. (2016). Understanding the Sharing Economy--Drivers and Impediments for Participation in Peer-to-Peer Rental. In System Sciences (HICSS), 2016 49th Hawaii International Conference on (pp. 4782-4791). IEEE.

Hoa. V.D. (2020). Developing of Sharing Economic Model on Airbnb platform in Vietnam Tourist Accommodation, Proceedings of the $3^{\text {rd }}$ conference on sustainable earth, mine, environment, 80-89

Hwang, G. J., \& Wu, P. H. (2014). Applications, impacts, and trends of mobile technology-enhanced learning: a review of 2008-2012 publications in selected SSCI journals. International Journal of Mobile Learning and Organisation, 8(2), 8395.

Islam, R., Islam, R., \& Mazumder, T. (2010). Mobile application and its global impact. International Journal of Engineering \& Technology (IJEST), 10(6), 72-78.

Jeng, Y. L., Wu, T. T., Huang, Y.M., Tan, Q., \& Yang, S. J. (2010). The add-on impact of mobile applications in learning strategies: A review study. Educational Technology \& Society, 13(3), 3-11.

Nah, F. F. H., Siau, K., \& Sheng, H. (2005). The value of mobile applications: a utility company study. Communications of the $A C M, 48(2), 85-90$. 
Liang, L.J. (2015). Understanding repurchase intention of Airbnb consumers: perceived authenticity, EWoM and price sensitivity (Doctoral dissertation).

Lu, Y., Zhao, L., \& Wang, B. (2010). From virtual community members to C2C e-commerce buyers: Trust in virtual communities and its effect on consumers' purchase intention. Electronic Commerce Research and Applications, 9(4), 346-360.

Mayer, R.C., Davis, J.H. and Schoorman, F.D., (1995). An integrative model of organizational trust. Academy of Management Review, 20(3), 709-734.

Mehdipour, Y., \& Zerehkafi, H. (2013). Mobile learning for education: Benefits and challenges. International Journal of Computational Engineering Research, 3(6), 93-101.

Moon, J. W., \& Kim, Y. G. (2001). Extending the TAM for a World-Wide-Web context. Information \& Management, 38(4), 217-230.

O'Connor, S., \& Andrews, T. (2018). Smartphones and mobile applications (apps) in clinical nursing education: A student perspective. Nurse Education Today, 69, 172-178.

Oliveira, T., Thomas, M., Baptista, G., \& Campos, F. (2016). Mobile payment: Understanding the determinants of customer adoption and intention to recommend the technology. Computers in Human Behavior, 61, 404-414.

Park, E., Baek, S., Ohm, J., \& Chang, H. J. (2014). Determinants of player acceptance of mobile social network games: An application of extended technology acceptance model. Telematics and Informatics, 31(1), 3-15.

Pavlou, P. A., \& Fygenson, M. (2006). Understanding and predicting electronic commerce adoption: An extension of the theory of planned behavior. MIS Quarterly, 30(1), 115-143.

Pappas, I. O., Giannakos, M. N., \& Sampson, D. G. (2017). Fuzzy set analysis as a means to understand users of 21 st-century learning systems: The case of mobile learning and reflections on learning analytics research. Computers in Human Behavior, 92, 646-659.

Singh, S., Srivastava, V., \& Srivastava, R.K. (2010). Customer acceptance of mobile banking: A conceptual framework. Sies Journal of Management, 7(1), 55

Tussyadiah, I.P., (2016). Factors of satisfaction and intention to use peer-to-peer accommodation. International Journal of Hospitality Management, 55, 70-80

Venkatesh, V., \& Davis, F. D. (2000). A theoretical extension of the technology acceptance model: Four longitudinal field studies. Management Science, 46(2), 186-204.

Venkatesh, V., Morris, M. G., Davis, G. B., \& Davis, F. D. (2003). User acceptance of information technology: Toward a unified view. MIS Quarterly, 27(3), 425-478.

Venkatesh, V., Thong, J.Y, \& Xu, X. (2012). Consumer acceptance and use of information technology: extending the unified theory of acceptance and use of technology, MIS Quarterly, 36(1), 157 - 178

Zhou, T. (2012). Understanding users' initial trust in mobile banking: An elaboration likelihood perspective, Computers in Human Behavior, 28(4), 1518 - 1525

Wang, W., Ngai, E. W., \& Wei, H. (2012). Explaining instant messaging continuance intention: the role of personality. International Journal of Human-Computer Interaction, 28(8), 500-510.

Webster, J., Trevino, L. K., \& Ryan, L. (1993). The dimensionality and correlates of flow in human-computer interactions. Computers in Human Behavior, 9(4), 411-426.

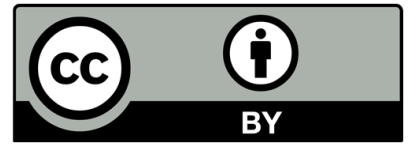

(C) 2021 by the authors; licensee Growing Science, Canada. This is an open access article distributed under the terms and conditions of the Creative Commons Attribution (CC-BY) license (http://creativecommons.org/licenses/by/4.0/). 